\title{
The Affordable Care Act and Trends in Insurance Coverage and Disease Awareness Among Non-elderly Individuals with Kidney Disease
}

\author{
Meera Nair Harhay, MD, MSCE ${ }^{1,2}$ and Ryan M. McKenna, PhD 3 \\ 'Department of Medicine, Division of Nephrology and Hypertension, Drexel University College of Medicine, Philadelphia, PA, USA; ${ }^{2}$ Department of \\ Epidemiology and Biostatistics, Drexel University Dornsife School of Public Health, Philadelphia, PA, USA; ${ }^{3}$ Department of Health Management and \\ Policy, Drexel University Dornsife School of Public Health, Philadelphia, PA, USA.
}

$\begin{array}{ll}\text { Abbreviations } \\ \text { ACA } & \text { Affordable Care Act } \\ \text { CHIP } & \text { Children's Health Insurance Program } \\ \text { CI } & \text { Confidence interval } \\ \text { CKD } & \text { Chronic kidney disease } \\ \text { CKD-EPI } & \text { Chronic Kidney Disease-Epidemiology Collaboration } \\ \text { eGFR } & \text { Estimated glomerular filtration rate } \\ \text { FPL } & \text { Federal poverty level } \\ \text { NHANES } & \text { National Health and Nutrition Examination Survey } \\ \text { NHB } & \text { Non-Hispanic black } \\ \text { NHW } & \text { Non-Hispanic white } \\ \text { US } & \text { United States }\end{array}$

J Gen Intern Med 34(3):351-3

DOI: $10.1007 / \mathrm{s} 11606-018-4713-2$

(c) Society of General Internal Medicine 2018

\section{INTRODUCTION}

Kidney disease afflicts approximately $10 \%$ of the United States (US) population and is its' ninth leading cause death. ${ }^{1}$ Though US individuals with kidney disease can receive Medicare if they qualify by age or require maintenance dialysis, younger individuals with earlier-stage disease are not afforded this coverage. Uninsured US individuals with kidney disease are more likely to be low-income and non-white, ${ }^{2}$ less likely to receive preventative care, ${ }^{2}$ and more likely to die or become dialysis dependent. ${ }^{3}$ Since 2010, minorities and low-income US individuals experienced substantial gains in insurance coverage under Patient Protection and Affordable Care Act (ACA) policies, particularly Medicaid expansion. ${ }^{4}$ The goal of this study was to examine whether similar trends were evident in insurance coverage and disease awareness among non-elderly US individuals with kidney disease.

\section{METHODS}

We analyzed eight waves of the National Health and Nutrition Examination Survey ([NHANES] 2001-2016), a nationally representative cross-sectional survey conducted in 2-year cycles. ${ }^{5}$ Kidney disease was defined as

Published online October 26, 2018 an estimated glomerular filtration rate (eGFR) of $<60 \mathrm{ml} /$ $\mathrm{min} / 1.73 \mathrm{~m}^{2}$ using the CKD-EPI or Schwartz equations for participants age $>$ or $\leq 18$ years, respectively, or a urine albumin to creatinine ratio $\geq 30 \mathrm{mg} / \mathrm{g}$. We used recommended calibrations and sampling weights. ${ }^{5}$ Kidney disease awareness was defined as affirmative responses to the survey question: "Have you ever been told you have weak or failing kidneys?"6 available through $2013 / 2014$. Medicare-eligible participants (including age $\geq 65$ ) and pregnant females were excluded, as were other races/ethnicities (due to small sample sizes).

Health insurance coverage was categorized as uninsured, private, or Medicaid/Children's Health Insurance Program (CHIP); race/ethnicity as non-Hispanic white (NHW), non-Hispanic black (NHB), or Hispanic; and family income as a percentage of the federal poverty level (FPL) as $0-138 \%, 139-250 \%, 251-400 \%$, or > $400 \%$. We estimated adjusted insurance coverage prevalence rates using marginal standardization from a multivariable multinomial logistic regression model adjusted for age, sex, income, and an interaction between survey wave and race/ethnicity. We then calculated age-, race/ethnicity-, and sex-adjusted insurance trends among individuals at $0-138 \%$ of the FPL. Kidney disease awareness was calculated by wave and by disease severity. Analyses were performed using Stata version 14.1 (StataCorp, College Station, TX). The study was approved by the Drexel University Institutional Review Board.

\section{RESULTS}

Participants' demographics and income were similar across between survey waves (Table 1). Adjusted insurance coverage rates were stable among NHW with kidney disease from 2001 to 2016 (Fig. 1). From 2001/ 2002 to 2009/2010, adjusted uninsured rates increased by 9.14 percentage-points among NHBs with kidney disease $(p=0.03)$ and by 7.0 percentage-points among Hispanics with kidney disease $(p=0.48)$. Adjusted Medicaid/CHIP coverage increased from 2001/2002 to 
Table 1 Demographic Characteristics of Non-elderly US Individuals with Kidney Disease Between 2001 and $2016(n=4685)$

\begin{tabular}{|c|c|c|c|c|c|c|c|c|c|}
\hline & \multicolumn{8}{|c|}{ NHANES wave } & \multirow{2}{*}{$\begin{array}{l}p \\
\text { value }\end{array}$} \\
\hline & $\begin{array}{l}2001 / \\
2002\end{array}$ & $\begin{array}{l}2003 / \\
2004\end{array}$ & $\begin{array}{l}2005 / \\
2006\end{array}$ & $\begin{array}{l}2007 / \\
2008\end{array}$ & $\begin{array}{l}2009 / \\
2010\end{array}$ & $\begin{array}{l}2011 / \\
2012\end{array}$ & $\begin{array}{l}2013 / \\
2014\end{array}$ & $\begin{array}{l}2015 / \\
2016\end{array}$ & \\
\hline Age (years) & $35(1.08)$ & $34(0.99)$ & $33(0.93)$ & $33(1.04)$ & $34(1.00)$ & $34(1.50)$ & $36(1.18)$ & $32(1.17)$ & 0.34 \\
\hline Female $(\%)$ & 59.28 & 58.18 & 61.70 & 59.26 & 60.20 & 52.62 & 61.35 & 59.00 & 0.24 \\
\hline Race and ethnicity & & & & & & & & & 0.99 \\
\hline Hispanic & 17.60 & 18.84 & 17.37 & 19.38 & 18.84 & 21.61 & 20.89 & 20.32 & \\
\hline Non-Hispanic white & 66.78 & 63.42 & 68.20 & 65.62 & 64.77 & 60.20 & 64.12 & 61.68 & \\
\hline Non-Hispanic black & 15.62 & 17.74 & 14.43 & 15.00 & 16.39 & 18.19 & 14.99 & 18.00 & \\
\hline Income (FPL \%) & & & & & & & & & 0.59 \\
\hline $0-138 \%$ & 26.40 & 23.81 & 22.21 & 25.93 & 27.63 & 28.31 & 29.12 & 25.49 & \\
\hline $139-250 \%$ & 18.79 & 21.76 & 18.64 & 20.72 & 18.36 & 14.80 & 20.64 & 21.52 & \\
\hline $251-400 \%$ & 19.91 & 20.68 & 23.27 & 16.12 & 16.65 & 15.61 & 18.31 & 19.76 & \\
\hline$\geq 400 \%$ & 34.90 & 33.74 & 35.89 & 37.24 & 37.36 & 41.28 & 31.93 & 33.23 & \\
\hline Insurance coverage $(\%)$ & & & & & & & & & 0.02 \\
\hline Private & 68.47 & 73.78 & 68.28 & 66.79 & 64.80 & 61.20 & 62.68 & 60.42 & \\
\hline Medicaid & 10.86 & 11.35 & 11.39 & 12.53 & 14.25 & 14.58 & 16.26 & 22.54 & \\
\hline Uninsured & 20.66 & 14.87 & 20.33 & 20.67 & 20.95 & 24.25 & 21.06 & 17.04 & \\
\hline $\begin{array}{l}\text { Informed of weak or failing } \\
\text { kidneys }(\%)^{1}\end{array}$ & 6.28 & 3.73 & 5.76 & 5.74 & 3.82 & 9.56 & 3.32 & NA & 0.02 \\
\hline
\end{tabular}

NHANES, National Health and Nutrition Examination Survey; FPL, federal poverty level

Values represent means (standard deviations) or column percentages

$P$ values from ANOVA or chi-squared tests, as appropriate

${ }^{I}$ Sample size $=2062$

$2009 / 2010$ by 6.6 percentage-points among NHBs $(p=$ 0.01 ) and decreased by 0.6 percentage-points among Hispanics $(p=0.80)$. From $2009 / 2010$ to $2015 / 2016$, adjusted uninsured status decreased by 6.4 percentagepoints among NHBs $(p=0.12)$ and increased by 2.3 percentage-points among Hispanics $(p=0.78)$. Medicaid/CHIP coverage increased from 2009/2010 to $2015 / 2016$ by 13.1 percentage-points among NHBs $(p=$ $0.001)$ and by 8.9 percentage-points among Hispanics $(p=0.003)$. Age-, race-, and gender-adjusted Medicaid/ CHIP coverage increased by 20.0 percentage-points $(p=$ 0.008 ) among participants within $0-138 \%$ FPL from $2009 / 2010$ to $2015 / 2016$, corresponding with an 9.2 percentage-point decrease in uninsured status (39.3 to $30.1 \%, p=0.23)$.

Overall, kidney disease awareness varied between waves (Table 1). In 2013/2014, 3.3\% of respondents reported kidney disease awareness. Stratified by disease severity, among participants with eGFR $<60 \mathrm{ml} / \mathrm{min} /$ $1.73 \mathrm{~m}^{2}, 6.9 \%$ were aware of kidney disease in $2013 / 2014$, whereas $0.9 \%$ of participants with eGFR $\geq$ $60 \mathrm{ml} / \mathrm{min} / 1.73 \mathrm{~m}^{2}$ and albuminuria reported kidney disease awareness.

\section{DISCUSSION}

In a nationally representative sample of non-elderly US individuals with kidney disease, Medicaid/CHIP coverage increased substantially among US NHBs, Hispanics, and low-income individuals with kidney disease from
$2009 / 2010$ to $2015 / 2016$. Nearly one-in-six non-elderly Hispanics and one-in-three non-elderly NHBs with kidney disease were covered by Medicaid/CHIP in $2015 / 2016$. Yet, over $30 \%$ of the lowest-income individuals with kidney disease were uninsured in 2015/2016, and kidney disease awareness remained low. Our study has important limitations, including use of a single measure of serum creatinine and albuminuria (misclassification bias), self-reported insurance coverage, and lack of detail on states of residence. Our results suggest that first-line Medicaid providers have an increasing role in identifying US minorities with kidney disease and in improving kidney disease awareness. Studies are needed to determine impacts of policies that restrict Medicaid coverage on US kidney disease outcomes.

Acknowledgments: MNH is supported by a grant (K23DK105207) from the National Institutes of Health (NIH)/National Institutes of Diabetes and Digestive and Kidney Diseases (NIDDK). The content is solely the responsibility of the authors and does not necessarily represent the official views of the National Institutes of Health.

Corresponding Author: Meera Nair Harhay, MD, MSCE; Department of Medicine, Division of Nephrology and Hypertension, Drexel University College of Medicine, Philadelphia, PA, USA (e-mail: mnh52@drexel.edu).

Author Contributions MNH and RMM designed the study, analyzed the data, interpreted the data and drafted and revised the manuscript; both authors approved the final version of the manuscript.

\section{Compliance with Ethical Standards:}

Conflicts of Interest: The authors of this manuscript have no conflicts of interest to disclose. 
a) Non-Hispanic White

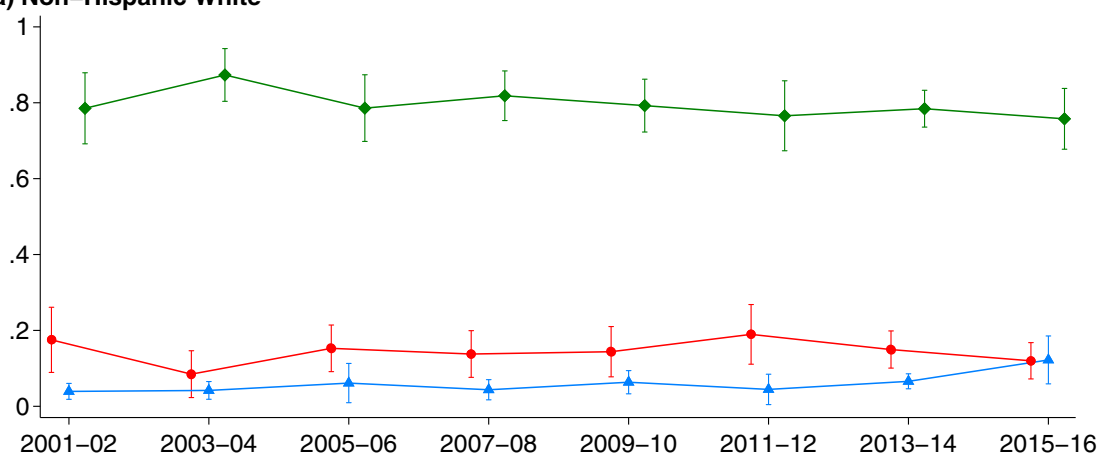

b) Non-Hispanic Black

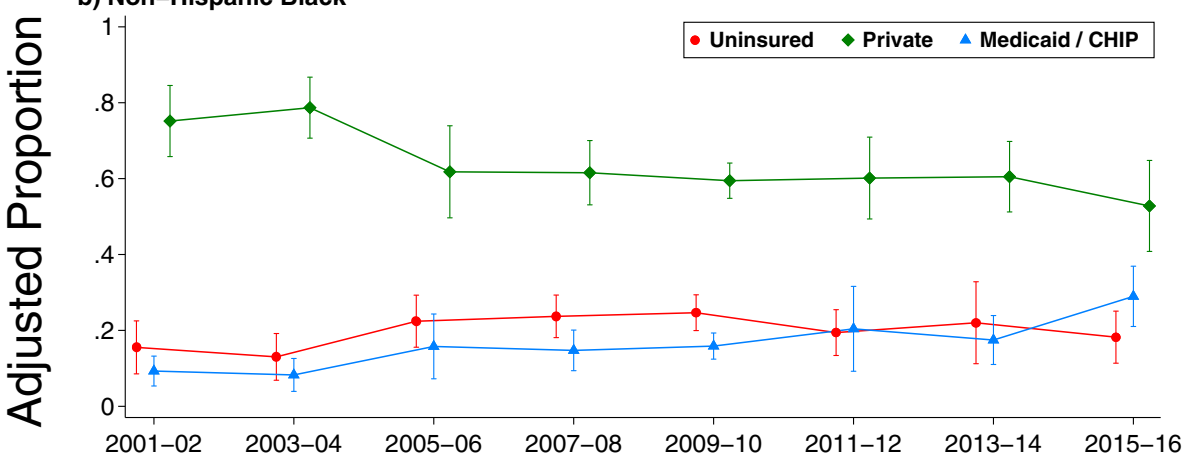

c) Hispanic

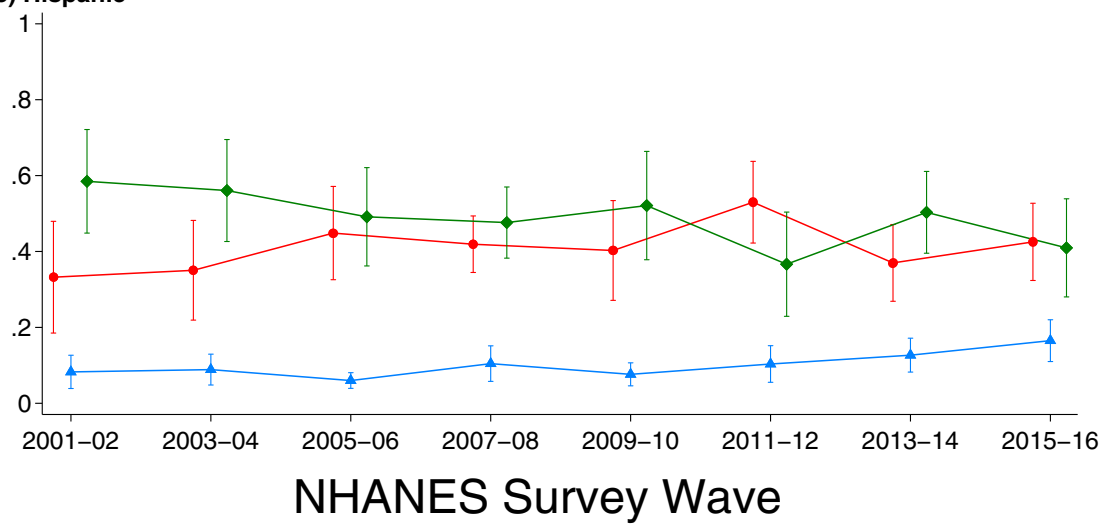

Figure 1 Age-, sex-, and income-adjusted trends in insurance coverage among non-elderly non-Hispanic white (A), non-Hispanic black (B), and Hispanic (C) US individuals with kidney disease, with 95\% confidence intervals $(n=4685)$.

\section{REFERENCES}

1. National Institute of Diabetic and Digestive and Kidney Diseases. Kidney Disease Statistics for the United States;Pages. Accessed at U.S. Department of Health and Human Services at https://www.niddk.nih.gov/ health-information/health-statistics/kidney-disease on September 12 2018.

2. Hall YN, Rodriguez RA, Boyko EJ, Chertow GM, O'Hare AM. Characteristics of uninsured Americans with chronic kidney disease. J Gen Intern Med. 2009;24(8):917-22.

3. Jurkovitz CT, Li S, Norris KC, Saab G, Bomback AS, Whaley-Connell AT, et al. Association between lack of health insurance and risk of death and ESRD: results from the Kidney Early Evaluation Program (KEEP). Am J Kidney Dis. 2013;61(4 Suppl 2):S24-32.

4. Lipton BJ, Decker SL, Sommers BD. The Affordable Care Act Appears to Have Narrowed Racial and Ethnic Disparities in Insurance Coverage and Access to Care Among Young Adults. Med Care Res Rev. 2017: 1077558717706575 .

5. Murphy D, McCulloch CE, Lin F, Banerjee T, Bragg-Gresham JL, Eberhardt MS, et al. Trends in prevalence of chronic kidney disease in the United States. Ann Intern Med. 2016;165(7):473-81.

6. Plantinga LC, Boulware LE, Coresh J, Stevens LA, Miller ER, 3rd, Saran R, et al. Patient awareness of chronic kidney disease: trends and predictors. Arch Intern Med. 2008;168(20):2268-75. 